\title{
ASPECTOS HISTÓRICOS NA NARRATIVA DE LÚCIO CARDOSO: O CASO DE MALEITA
}

\section{HISTORICAL ASPECTS IN LÚCIO CARDOSO'S NARRATIVE:}

THE CASE OF MALEITA

Luís Alberto dos Santos Paz Filho*
* luis.alberto@acad.pucrs.br

Oossui Graduação em Letras (português e Literatura) pela Pontifícia Universidade Católica do Rio Grande do Sul (2017), com bolsa PROUNI, onde atuou como bolsista de Iniciação Científica no período de 2013 a 2017, tendo participado de pesquisas nas áreas de literatur brasileira autobiográfica e memorialística, e literaturas de língua portuguesa de origens europeia e africana do século XXI. Possui Mestrado em Teoria da Literatura (2019) pela Pontifícia Universidade Católica do Rio Grande do Sul, sendo bolsista CNPq. Atualmente é doutorando em Teoria da Literatura pelo Programa de Pos-Graduação em Letras da Pontifícia Universidade Católica do Rio Grande do Sul sendo bolsista Capes.

RESUMO: o presente trabalho tem por objetivo realizar uma análise da obra Maleita, do escritor Lúcio Cardoso, buscando propor uma leitura na qual a obra responda - ou levante questões - acerca do fenômeno do hibridismo entre literatura e historia. Ao partir de questionamentos e pressupostos levantados por Peter Burke e György Lukacs a respeito das relações entre literatura e história, bem como caracteristicas do romance histórico chamado tradicion $\mathrm{em}$ comparaça ao intitula novoromance historico, este estudo pretende exibir uma leilura da obra camdosiana com a intença de mostrar a não se não se encontra enclausurado em uma crítica datada. Dessa forma os aspectos históricos na obra de Cardoso seráo apresentados sob duas perspectivas: uma que diz respeito a uma proposta biográfica do romance e outra que se detém ao estudo global de algumas caracteristicas do novo romance histórico.

PALAVRAS-CHAVE: Romance histórico; romance biográfico; romance brasileiro.
ABSTRACT: The aim of this paper is to analyze the work Maleita, written by Lúcio Cardoso, seeking to propose a reading in which of hybridism between literature and history. From questions and assumptions raised by Peter Burke and György Lukacs about the the so-called traditional historical novel compared to the so-called this study aims to display a reading of the with the sintention of showing the plausibility of its work with the intention of showing the plausibility of its ins dated criticism. Thus, the historical aspects in Cardoso's work will be presented from two perspectives: one that concerns a biographical proposal of the novel and another that focuses on the global study of some characteristics of the new historical novel.

KEYWORDS: Historical novel; biographical novel; brazilian novel. the work answers - or raises questions - about the phenomenon relationship between literature and history, as well as features of 
1. No presente trabalho, não se pretende dissertar acerca do brasileira no período já citura tampouco ambiciona dar conta de explicar o vasto projeto literário elaborado por Lúcio Cardoso. Sugere-se, por isso, aos interessados na obra do autor, conferir os trabalhos produzidos por grandes pesquisadores de sua obra, como Valeria Lamego, Beatriz Damasceno, Elizabeth da Penha Cardoso, Cássia dos Santos, Ésio Ribeiro, Ruth Silviano Brandão, Enaura Quixabeira Rosa e Silva, Maria Terezinha Martins, Mário Carelli e outras e outros fascinados pelo dominio da linguagem exercido por Lúcio.
CONSIDERAÇÕES INICIAIS: UMA APRESENTAÇÃO DA

\section{MALEITA}

Lançado em 1934, Maleita é o romance de estreia de Lúcio Cardoso. O autor, que é mineiro, tem como marca registrada em sua literatura a preferência pelo aprofundamento de aspectos psicológicos da trama e das personagens, o que revela, quase sempre, uma complexa natureza humana na qual os indivíduos participam de um espaço conflituoso que lhe corrompe, nega-lhes o acesso à esperança e, em última instância, tra ta com crueza a capacidade de gerar o mal. A produção cardosiana ficou representada como pertencente a uma das vertentes mais fortes da literatura brasileira produzida no decorrer da década de 30 do século XX: se, por um lado, havia o chamado romance social (que, por vezes, na historiografia literária confundiu-se com o romance produzido no nordeste do país), por outro se erguia o intitulado romance introspectivo. Embora a nomenclatura não seja muito agradável, sobretudo porque parece diminuir de alguma forma a atividade artística das autoras e dos autores desse "grupo", este último é onde Lúcio ${ }^{1}$ se encontra, ao lado de nomes como Octavio de Faria, Cornélio Penna e, mais tarde, Clarice Lispector.

De acordo com Cássia dos Sa ntos, em Polêmica e controvérsia: o itinerário de Lúcio Cardoso de Maleita a O enfeitiçado
(1997) seria importante estabelecer um contexto do cená rio literá rio pouco anterior ao lançamento da obra de Lúcio, para compreender a recepção de seu romance pela crítica. Dos lançamentos anteriores a Maleita: José Américo de Almeida la nçara, em 1928, o romance $A$ bagaceira. A ele se seguira m O quinze, de Rachel de Queiroz, em 1930, e O país do carnaval, de Jorge Amado, em 1931. No ano seguinte, surgia Menino de engenho, de José Lins do Rego e, finalmente, em 1933, eram publicados Caetés de Graciliano Ramos e Os corumbas, de Amando Fontes. Nos livros citados, com os quais seus autores estreavam na literatura, bem como em outros que publicariam ao longo desta década, era possível reconhecer pontos em comum. Ambientados no Nordeste, tinham como temática, em geral a seca, a decadência dos engenhos e suas consequências. Buscavam contar a história do ponto de vista dos oprimidos, dos miseráveis, retratando o cotidiano sofrido da parcela pobre da população. Além disso, procuravam descrever fielmente o linguajar e os costumes dos habitantes da região que lhes servia de cenário (SANTOS, 1997, p. 17).

A obra acaba sendo elogiada por críticos - inclusive o temido Agripino Grieco, que compara Lúcio a Julien Green. Porém, Lúcio, confuso, acredita que foi colocado como integrante do grupo dos chamados "escritores 
regionalistas" da época, devido ao tema da obra. Esta é, aliás, uma das grandes preocupações que o assolarão ao longo de sua vida, levando-o a criar certas antipatias com aqueles devido a declarações polêmicas de sua parte. O trabalho, de forma alguma, pretende insinuar que o grupo dos escritores que produziam uma literatura mais voltada para a denúncia social e para as questões regionais é inferior ao grupo do qual fazia parte Lúcio Cardoso. Não cabe aqui um juízo de valor, até porque o campo da Literatura permite a coexistência de diversas manifestações artísticas, e não há ganho para ninguém tentar estabelecer uma hierarquia qualitativa. Estas informações mostram-se relevantes para a construção da visão particular de Lúcio sobre o ambiente literário de sua época, revelando também seus objetivos dentro da literatura nacional.

Sobre uma das primeiras edições de Maleita, diz Cavalcanti Proença sobre Lúcio: "é ele um escritor muito jovem, mas de essência individualíssima [...] mal entrando na casa dos vinte anos, e já dominando a composição e a expressão para dispor os episódios, às vezes trágicos, e a tessitura sempre dramática do seu romance". De acordo com Cássia dos Santos, em Polêmica e controvérsia em Lúcio Cardoso (2001) muito embora não reproduzisse fielmente o modelo dos livros que a inspiraram, Maleita foi recebida como mais uma obra regionalista e, nesta condição, saudada por outros importantes nomes da crítica como Jayme Barros e Eloy Pontes. (SANTOS, 2001, p. 25)

Nelson Werneck Sodré, em História da literatura brasileira (1995), diz que "Lúcio Cardoso, na linha do romance nordestino, mas com temas do sudeste, publica Maleita, em 1934, e Salgueiro, em 1935; está pagando tributo ao modelo dominante". (SODRÉ, 1995, p. 555)Por sua vez, Alfredo Bosi, em História concisa da literatura brasileira (1994) inicia seu balanço a respeito da obra cardosiana valorizando o autor desde o seu primeiro romance: "Desde Maleita [...], Lúcio Cardoso revela pendor para a criação de atmosferas de pesadelo. Já em 1936, com A luz no subsolo, o escritor se definiria pelo romance de sondagem interior a que lograria dar uma rara densidade poética" (BOSI, 1994, p. 413). Nota-se que Bosi destaca um perfil mais apurado da literatura cardosiana, enfatizando a linha que o autor (per)seguiria ao longo de sua vida.

A partir da breve retomada elaborada a respeito da produção e recepção da obra, pode-se observar a importância dela para o lançamento de Lúcio no cenário 
literário nacional. Muito embora ele tenha percorrido um ca minho que o afasta, até certo ponto, destes primeiros experimentos como romancista, Maleita possui ainda outras qualidades estéticas e formais que fazem com que sua vitalidade perdure. Uma delas é seu caráter plurissignificativo: estaria Lúcio ensaiando uma proposta de romance biográfico? Ou ainda: seria este um exercício de um novo romance histórico? Se estas questões não serão plenamente respondidas (e adianta-se que não serão), ao menos serão postas em jogo nos tópicos a seguir.

\section{MALEITA: UMA PROPOSTA BIOGRÁFICA?}

No romance, o protagonista-na rrador surge como um desbravador que deve construir um mundo civilizado em uma região onde os nativos que a habitam apresentam hábitos e atividades "primitivas" - segundo a perspectiva adotada pela narrativa, cujo foco narrativo em terceira pessoa traduz a visão de mundo de Joaquim. Revestido de características que o tornam um típico herói de romance de aventura - ao menos a um primeiro olhar - o protagonista é contratado pela família Menezes, formada por importantes comerciantes de Curvelo (cidade mineira onde nasceu também o autor, Lúcio), para fundar Pirapora, às margens do rio São Francisco. Ele se muda para lá recém-casado com sua esposa Elisa. Suas atribuições englobavam construir o porto comercial e representar "com todas as regalias, a companhia Cedro e Cachoeira de Fiação e Tecido. Teria a obrigação de organizar o comércio local e incentivar a vida no povoado nascente" (CARDOSO, 2005, p. 10)

Em Maleita há a elaboração de dois tipos de movimentos: um de caráter exterior, que diz respeito, sobretudo, à viagem a Pirapora por parte de Joaquim e Elisa, mas também dos viajantes que chegam para trabalhar no vila rejo, vindos de outros estados do Brasil; e um de modelo interior, que insta ura, através da narrativa, um espaço no qual os espectadores mergulham, intensa mente, no âmago das personagens - destaque para Joaquim - descobrindo o que sentem e como se percebem a cada acontecimento da cidade. Este último aspecto, é preciso ressaltar novamente, marca a literatura cardosiana de forma geral: somos convidados-intrusos nas entranhas dos indivíduos, mexendo e sentindo cada engrenagem que se move quando o mal funciona - e sempre funciona - no plano diegético. Esse mal é apresentado sob diversas nuances nas obras de Cardoso: seja através da negação de Deus ou qua ndo brota, a través dos pensa mentos e ações, de dentro do indivíduo. Este caso é o mais recorrente, o que leva a cogitar a tendência de o sujeito ser o causador do próprio mal em sua vida. Assim, seja devido à doença que assola as criaturas desde as primeiras páginas 
do romance - e que contribuirá com a desintegração do a mbiente -, seja devido ao choque de culturas através da violência, os movimentos internos nas personagens ocorrem em grande intensidade, mas são consequências também das condições climáticas e espaciais que parecem ditar o ritmo da vida por lá. Neste sentido, o espaço é uma das características fundamentais a serem a nalisadas no romance de Lúcio Cardoso.

Poder-se-ia dizer que o rio São Francisco rouba, sob um ponto de vista metafórico, o papel de protagonista da narrativa de Joaquim. De acordo com Jean Chevalier, em Dicionário de símbolos (1998), "as significações simbólicas da água podem reduzir-se a três temas dominantes: fonte de vida, meio de purificação e centro de regeneração" (CHEVALIER, 1998, p. 58). Um dos quatro elementos fundamentais da natureza, ao lado do fogo, da terra e do ar, a água é, em muitas mitologias, a origem da vida. $\mathrm{O}$ seu poder é intensificado quando pensado em seus possíveis movimentos: a água que se desloca infinita mente, como o mar ou o rio, é uma força de impulsão dos acontecimentos. Ela gera a vida, mas também faz com que ela continue existindo, mudando, adaptando-se. Nesse sentido, o rio São Francisco da obra é também uma ferramenta de transporte entre os tempos: um fluxo de passado para o futuro que gera um presente mutável, constante e imprevisível. As turbulências das águas profundas escondidas sobre o brilho pacífico da borda mais rasa são como as personagens do romance de Lúcio: almas perturbadas e violentas que se escondem na normalidade da condição humana. Desse modo, as águas de Maleita parecem se aproximar da Mitologia Egípcia, na qual "Num", o mais antigo Deus Egípcio, simbolizava a água, de onde emergiu a criação. Dentre suas qualidades, destacam-se: a turbulência, a escuridão e a falta de limites, simbolizando ta mbém a morte, as cala midades e devastações.

Faz-se interessante notar, contudo, outro aspecto concernente ta mbém à obra de Lúcio: seu cunho biográfico. Em Maleita, conforme dito anteriormente, o protagonista é Joaquim. O nome da personagem é o primeiro elemento que estabelece conexão com o mundo empírico: este é também o nome do pai de Lúcio. Mas o segundo fato é o mais importante: o pai de Lúcio teria participado, de fato, da fundação de Pirapora e contaria muitas histórias deste tempo em casa para os filhos. Assim, levanta-se a pergunta: seria Maleita uma obra que presta homenagem ao pai de Lúcio? Estaria ele ficcionalizando a vida de seu pai em uma narrativa de caráter fundador que, em última instância, faria uma revisão da história das Minas Gerais? 
Há outro ponto que, de certa forma, foge à leitura aqui proposta, mas que contribui à hipótese levantada: esta não é a única vez que a personagem Joaquim aparecerá no percurso literário de Lúcio. Em seu romance de 1943 intitulado Dias perdidos, Joaquim retorna, dessa vez assumindo também uma figura paterna no romance, só que sob outra ótica: se em Maleita o que se constrói é a imagem do pai heroico, em Dias perdidos é a do pai fracassado.

A problemática da forma biográfica já se apresentava nos questionamentos de György Lukács, que, por volta de 1936 (mesma época de publicação de obras de Lúcio Cardoso), escrevia a obra O romance histórico. Em sua obra, Lukács ressalta o papel da vida como elemento constitutivo de narrativas, abordando a forma como a memória e os fatos verídicos sobre a trajetória de vida do autor influenciavam a proposta da obra literária. Este fenômeno propunha uma contraposição ao heró construído em obras de séculos anteriores, cujo ideal era praticamente inatingível, estabelecendo uma evidente distância entre o protagonista da obra literária e seus leitores. Destaca-se, portanto, o excerto a seguir presente na edição de 2011 de $O$ romance histórico:

As produções significativas do mais novo romance histórico indicam claramente uma tendência à biografia. $O$ conta to imediato com a vida é, em muitos casos, a moda que domina hoje a beletrística histórico-biográfica. No entanto, nos casos realmente importantes, ela é pouco mais que um contato formal. O caráter popular da forma biográfica no romance histórico a tual provém antes do fato de que seus mais expressivos representantes desejam contrapor ao presente grandes personagens modela res do ideal humanista, apresentando-as como exemplos, precursores vivos e redivivos das grandes lutas a tuais. (LUKÁCS, 2011.p. 366)

A partir dessa perspectiva, levanta-se a possibilidade de, em Maleita, Cardoso utilizar-se desse modo de expressão para conceber um romance que flerte com os gêneros de memórias romanceadas ou biografias literárias. Nesse caso, o herói elaborado poderia ser a figura paterna (de Lúcio) que, conforme fora mencionado, retorna em diversas de suas obras.

Uma vez que este estudo pretende mais fazer provocações do que afirmações definitivas, passemos a analisar como é configurado o personagem Joaquim, no que concerne a como suas a titudes muda $m$ ao longo da narrativa e no que implicam seus atos e seus posiciona mentos em relação ao espaço e aos habitantes de Pirapora. Vale destacar que, segundo Lukács, (2011), 
o romance não exige necessariamente a figuração de homens importantes em situações importantes. Em certos casos, ele pode abdicar disso, apresentando as personagens significativas sob uma forma que dê a seus traços uma expressão puramente interna e moral, de modo que a oposição figurada entre o cotidiano mesquinho da vida e esse significado puramente intensivo do homem, essa inadequação entre homem e ação, entre interior e exterior, torne-se o atrativo próprio do romance. (LUKÁCS, 2011, p. 159)

Dessa forma, destaca-se que a primeira postura adotada por Joaquim é a do diálogo, ao tentar estabelecer uma conexão com os habitantes e trabalhadores do vilarejo. É preciso, contudo, ressaltar que Joaquim é visto como um intruso desde o início. Ele é o ser externo ao am biente. Além disso, ele possui uma noção bem afirmada a respeito de o que é cultura, como se deve trabalhar e o que precisa ser feito para que o progresso aconteça a Pirapora. Estas são visões e atitudes do homem branco que assume uma postura de colonizador e salvador. Ele nunca se sente parte integrante e equânime do local. Ele está no topo de uma hierarquia por ele estabelecida graças ao poder do capital e por vir de uma cidade em pleno desenvolvimento mercantil e urbano. Em uma das passagens da narrativa, há avaliação:
O trabalho paralisado. Os adobes empilhados, rachando ao sol, os trabalhadores conversa ndo sobre a doença. As asas dos urubus feriam um ponto qualquer. As falas arrastadas morriam sem resposta. Súbito, um se declarava com dor de cabeça. Recolhia-se e delirava no abandono das palhoças [...] nas casas, o berreiro denunciava o dra ma. Os enterros eram feitos à moda do sertão. O morto, a tirado dentro de uma colcha de chita[...] A mortalidade crescia. Já não se enterrava mais. Os corpos eram atirados no mato. Cada vez em maior número, os urubus desciam, sombrios, sobre a carniça [...] Cerrava os olhos e só desejava que a morte aniquilasse tudo ou que o rio varresse aquela aldeola trágica, onde o sofrimento vibrava com tanta força em todas as almas (CARDOSO, 2005, pág. 153-160)

$\mathrm{Na}$ obra cardosiana, abre-se espaço para a individualização dos seres: cada um, a seu modo, é responsável por colorir o espaço da vida com seus próprios amores e temores. Não se costuma privilegiar o espaço das ações externas às personagens - é, antes, com a natureza de cada indivíduo que Lúcio se preocupa. Temas como a religiosidade e sexualidade aparecem para revelar maneiras particulares de se alcançar a desgraça ou o sublime.Ao sublinhar as identidades das personagens, o espaço também é contornado, porque há uma relação de cumplicidade entre estas estruturas. Assim, em Maleita, 
ao mergulhar nos pensamentos, desejos e angústias dos indivíduos, o narrador revela, pouco a pouco, a Pirapora que dali emerge em seus contornos mais enigmáticos e obscuros.

De posse da minha nomeação, senti-me outro. Era qualquer coisa mais do que um reles aventureiro. Tinha direito para manter a lei, conduzir a vida, que começava, por outro caminho. Os meus atos já não seriam meras intrujices. Seriam a vontade do subdelegado. (CARDOSO, 2005, pág. 88)

Fiquei mais velho, mais áspero. Os dias de agitação pesaram sobre mim. Percebia que já não era o mesmo e em vão me esforçava para readquirir a tranquilidade passada. (CARDOSO, 2005, pág. 96)

Estabelece-se uma relação que peca na capacidade de desenvolver algum tipo de empatia. $\mathrm{O}$ outro é visto com certa bestialidade em seus traços e em seu comportamento. A sexualidade aflorada das personagens, por exemplo, provoca uma fusão entre o espaço (como os sons e os cheiros da natureza) e dos próprios seres (os odores, os movimentos). O fato de andarem nus e de cultuarem uma religião distinta da sua, com hábitos musicais e dançantes os torna, aos olhos de Joaquim - cristão - primitivos que precisam ser salvos.
Com o passar do tempo, Joaquim vai perdendo a razão e se tornando irritadiço e descontrolado, chegando ao ponto de torturar e prender nativos que se rebelam às suas ordens. Trata-se de uma briga de valores: os nativos versus Joaquim, que tenta impor seu modo de ver o mundo e de agir sobre eles. Neste sentido, a obra adquire um valor histórico mais profundo ao abrir margem para se pensar em processos de colonização e dominação. Observam-se o trecho a seguir:

Era a primeira vez que chorava na minha vida. Nem mesmo nos dias tormentosos da varíola, a minha emoção havia chegado a tal intensidade. Mas, vendo a alegria da gente miserável da terra, sentindo que eu conseguira salvar o povoado, uma alegria intensa, uma comoção sobre-humana vergava-me como eu nunca supusera ser capaz. (CARDOSO, 2005, pág. 190)

A personagem chega ao ponto de considerar-se um benfeitor. Já não é possível saber se a ilusão vivida por Joaquim se dá unicamente por um otimismo esperançoso em estar fazendo seu trabalho de forma adequada ou ta mbém por consequências da doença que se espalha pela região, consumindo a sanidade de todas e de todos. Neste sentido, caberia aqui uma pergunta - sem resposta, mas que sempre possibilita a reflexão e eventuais descobertas 
sobre um novo modo de se olhar para um mesmo objeto: seria este personagem, que se confunde com a ideia empírica do pai do autor, uma alegoria da instituição familiar representada ao longo da história tradicional? Podería mos compreender Joaquim como a ficcionalização de um modus operandi de uma Minas Gerais de final de século XIX e início do século XX?

\section{RECURSOS HISTÓRICOS NO ROMANCE OU \\ ASPECTOS ROMANESCOS DE UMA HISTÓRIA}

De acordo com Hugo Aust, em seu texto "O romance histórico e suas formas", presente no livro Literatura e história: encontros contemporâneos (2016), "romances históricos se revelam, até mesmo quando não pretendem ser romances históricos" (AUST, 2016, p. 10). Se o romance histórico se apresenta como uma possibilidade de narrativa histórica, em Maleita, a fundação de Pirapora, fato histórico, é ficcionalizada de forma a se atribuir importância não ao acontecimento exclusivamente em si, mas aos processos que levaram a tal ação e, talvez ainda mais importante, às personagens que participa $m$ do mundo ficcional. Por não serem figuras heroicas gravadas nos livros de história, um dos grandes valores da obra de Lúcio Cardoso, uma vez realizada a leitura a partir de pressupostos que norteiam para uma análise de obra que se utiliza de material histórico como fonte de sua criação, está no protagonismo do espaço e das personagens, que desmascaram qualquer possibilidade de fingimento e se entregam aos problemas e às dúvidas que assola m qualquer indivíduo em qualquer tempo e em qualquer lugar. Esta quase generalização da huma nidade das personagens recebe um tratamento complexo e aprofundado que lhe reveste de singularidade histórica: são criaturas envoltas em um processo importante para a região das Minas Gerais, mas que confessam, em seus mistérios, a fraqueza, a cobiça e o desejo, que é tão mundano e geral que causa uma identificação imediata no leitor. Assim, além do aspecto biográfico que a obra apresenta, há também uma revisão dos fatos históricos através de uma lupa que mira não para os acontecimentos gravados nos manuais de história, mas às personagens que dele participaram. Neste caso, a obra alia-se à tendência observada já por Lukács, em $O$ romance histórico, de que as figuras humanas não são revestidas de notoriedade e fama. São, antes, criaturas comuns e ex-cêntricas que ganham o palco da narrativa.

Conforme Peter Burke, em seu texto "A nova história, seu passado e seu futuro", que compõe a obra $A$ escrita da história: novas perspectivas (1992), a chamada "nova história", originada na década de 70 do século XX (por conseguinte, posterior à produção de Cardoso), passa a se interessar por toda a atividade humana: "o que era previamente 
considerado imutável é agora encarado como uma "construção cultural", sujeita a variações, tanto no tempo quanto no espaço" (BURKE, 1992, p. 2), modificando a perspectiva de generalização salientada anteriormente. Dessa forma, não se pretende mais construir narrativas que almejem relatar "A história", mas antes, "uma história" ou uma possibilidade, dentre tantas, de uma perspectiva sobre uma história. Este fato revela em si o caráter híbrido que as narrativas históricas passam a assumir: uma obra literária que se utiliza de material histórico parece confundir facilmente o leitor: trata-se de verdade ou invenção? Embora não entremos aqui em uma longa discussão acerca dos significados de verdade e de ficção, tratemos da última não como mentira, mas como um método de elaboração discursiva presente na literatura. Sob este ângulo, Lúcio Cardoso joga com o papel da ficção: Minas Gerais é, além de sua terra natal, ambiente discursiva mente construído em diversas de suas narrativas, se não de maneira explícita nas entrelinhas. A história de Pirapora, distrito do estado de Minas, provoca, com a obra, um discurso híbrido que aproxima tanto autor empírico de sua vida quanto as personagens do plano diegético.

Conforme salienta Carlos Roberto da Silva, em No rumo(r) do rio: notas de leitura de Maleita, de Lúcio Cardoso (2013), o jogo meta histórico proposto na obra amplia a qualidade literária da obra: Maleita, além de lançar o olhar sobre momentos de governos totalitários, não permite o esquecimento dos efeitos da escravidão e dos processos colonizadores, pois, mesmo que em som rouco e sob pouca luz, traz um outro tempo, um outro povo e outras histórias à tona, para, em meio à insta uração de um governo dita torial (governo Vargas), fazer emergir um discurso de um tempo irruptivo e não linear que nos remete a dados antigos, agora novos porque esquecidos, da história nacional. (SILVA, 2013, p. 21)

O senso estético, que muitas vezes é questionado em obras do gênero está presente não como um acessório à narrativa da história, mas como condição da construção do discurso literário. Na obra de Lúcio Cardoso, o mote histórico assinalado percorre um caminho paralelo ao desenvolvimento literário em todas as facetas que se pensam ao se conceber uma crítica a um romance de outra ordem: espaço, tempo, personagem, narrador e discurso são elementos constituintes do real inventado - ou da invenção imaginada da realidade.De acordo com Aust (2016),

o romance histórico trata de ações políticas do passado, mais ou menos conectados com as ações privadas de uma história inventada. Suas ações são processos multiplamente 
condicionados e resultam em um evento histórico, no qual o público e o privado, o político e o pessoal, o mutável e o constante, o cálculo racional e o a feto passional a tua m em conjunto. (AUST, 2016, p. 20)

Sob esta perspectiva, o romance histórico trata de plausibilidades de um enredo que não aconteceu - mas que poderia ter acontecido. Ou ainda, que aconteceu, mas não exatamente desta forma. Porque é este o valor da expressão literária em confluência com o material vivo da história: o efeito simbólico de possibilidades. Assim, o que ocorre são discursos sobre os discursos da história. Não cabe aqui discutir como ocorreu exatamente a fundação da cidade de Pirapora nas Minas Gerais, mas sim o modo como Lúcio Cardoso transforma o acontecimento em ficção e quais os recursos que ele utiliza ao propor este jogo. No caso em análise, Maleita utiliza o espaço como uma dimensão polivalente, a tua ndo como dominador das personagens, visto que ele parece controlar suas ações e guiá-las ao erro (com as forças do rio, por exemplo), mas ta mbém colocando em cheque o que se entende como habitat, uma vez que Pirapora é palco para o confronto entre os nativos e os estrangeiros que chega m para trabalhar ou controlar as terras, como é o caso de Joaquim.
Pode-se pensar no término da narrativa em questão: a fundação da cidade não se dá de maneira pacífica, e as consequências para tal acontecimento leva $\mathrm{m}$ as personagens ao extremo. Assim, não há a linearidade de uma jornada heroica. O personagem não "vence após enfrentar as dificuldades da vida e todos alcançam o seu final feliz". Pelo contrário, é preciso abdicar de quase tudo para que o objetivo seja alcançado. De acordo com Burke (1992),

Por mais que lutemos arduamente para evitar os preconceitos associados a cor, credo, classe ou sexo, não podemos evitar olhar o passado de um ponto de vista particular. O relativismo cultural obviamente se aplica, tanto à própria escrita da história, qua nto a seus chamados objetos. Nossas mentes não refletem diretamente a realidade. Só percebemos o mundo através de uma estrutura de convenções, esquemas e estereótipos, um entrelaçamento que varia de uma cultura para outra. (BURKE, 1992, p. 4)

Assim, ao direcionar o olhar para a obra de estreia de Lúcio Cardoso, algumas questões retornam: muitos críticos, ao longo da carreira literária de Lúcio, consideraram ele e o chamado "Grupo dos espiritualistas" (que produziam uma literatura voltada para as ações internas das personagens, as expressões da alma e questionamentos metafísicos e filosóficos que, em última instância, de 
acordo com esta perspectiva, se opunham a um grupo que produzia uma literatura preocupada com questões socia is mais explícitas, como as mazelas da desigualdade econômica e a violência) como "alienados", sobretudo sob um ponto de vista político. Maleita e Salgueiro, primeiros romances de Lúcio, talvez tenham sido suas únicas obras a não sofrerem desta crítica, por terem sido associadas ao romance produzido no nordeste do país na mesma época (comparava-se a autores como José Lins do Rego e Rachel de Queiroz). No entanto, com as perspectivas que o ano de 2020 permite a um leitor, questiona-se: não estaria Lúcio provocando a escrita da história tradicional ao dar voz e espaço para personagens assombradas por sua pequenez, seja nas ruas da Lapa, no Rio de Janeiro, seja nas estradas empoeiradas de uma Minas Gerais (sempre vilã de suas histórias)? Não faria parte de seu projeto artístico reescrever a história de seu estado construindo enredos sufocantes nos quais as personagens parecem condenadas ao mal, como em $A$ luz no subsolo? Não seria Mãos vazias um retrato das relações abusivas entre um casal tradicional - $\mathrm{o}$ único modelo aceito moralmente pela sociedade: constituído por um homem e uma mulher? Não poderia Dias perdidos estar assumindo a corrupção dos valores fa miliares? E, o que mais interessa para o estudo aqui proposto, não seria Maleita um primeiro passo para uma denúncia da própria história através da literatura, na qual a história tradicional se ocupa de privilegiar um modelo específico de herói?

\section{CONSIDERAÇÕES FINAIS}

De acordo com as consideraçoes inicia is, este trabalho pretendeu mais do que fazer a firmações, provocar reflexões através de perguntas que colocam a obra tratada em um novo movimento de leitura e análise. Nenhuma escolha é ingênua, portanto deve-se salientar, outra vez, a importância e a crença na relevância do estudo desta obra: Maleita representa a estreia de Lúcio Cardoso na literatura nacional com o gênero romanesco. $\mathrm{O}$ autor mineiro publicou uma grande diversidade de obras em gêneros distintos, da poesia ao romance, passando pelo conto e pelo teatro. Ainda assim, é o romance o gênero no qual mais se destacou em termos de crítica e recepção.

O presente estudo mirou sua proposta no estudo do romance como sendo uma obra de cunho histórico. Neste sentido, optou-se por abrir dois caminhos possíveis que, em última análise, conversem e convergem para o mesmo ponto da revisão histórica a partir da ficcionalização romanesca. São eles: o caráter biográfico e o fato histórico recriado. Entende-se que, em ambos os casos, o olhar deve recair sobre o trabalho literário realizado pelo autor, que se utiliza das artimanhas ficcionais para 
conceber um mundo diegético no qual as personagens e o ambiente se sobressaem em relação às ações externas propria mente ditas. Por isso, pensar Maleita como um romance histórico ou, utilizando os termos aqui depreendidos, um romance de aspectos históricos, diz respeito também a renovar a crítica feita sobre a obra cardosiana.

Se, por um lado, conforme dito anteriormente, a crítica elaborou uma visão definitiva sobre a obra de Lúcio em seu tempo, a crítica posterior pouco tratou de revisá-la. Seus dois primeiros romances aparecem deslocados em seu próprio projeto literário, como se fossem apenas experiências temáticas que antecedem seu a madurecimento artístico. Não há de se negar que são dois romances um pouco diferentes temática e formalmente quando comparados às obras sucessoras, no entanto, é preciso registrar algumas questões a respeito, sobretudo a Maleita, obra tratada com mais atenção neste estudo: em primeiro lugar, a principal ca racterística da literatura cardosiana já existe neste romance: o plano das ações internas é o mais valorizado, bem como os temas do mal e os símbolos da noite e do obscuro se fazem presentes em abundância. Embora pareça, sob uma primeira olhada, um romance de cunho regionalista, é preciso defender que a obra vai além, não permitindo que a crítica social ou a denúncia das más condições de um povo (que existe na obra, evidentemente) se sobressaiam às qualidades e às técnicas literárias utilizadas. Afinal de contas, a literatura possui um dever a ser cumprido exclusiva mente consigo própria - os questionamentos, os ensinamentos, as reflexões e as percepções sobre o indivíduo e o mundo passíveis de serem tomados pelo leitor de uma obra são acréscimos importantes e valorizados, mas estamos a tratar essencialmente do aspecto laboral da arte como um produto artístico; e, em segundo lugar, o romance parece responder a perguntas que ainda não tinham sido feitas - mas que provocaram afirmações depois de seu lançamento -, mas que o jovem Lúcio já previa, em certa medida, acontecer: o que constitui o cará ter de um sujeito? É possível, sob boas alegações, ser tomado pelo mal? O espaço pode transformar um indivíduo? A crítica determinou um tipo de resposta a estas questões, mas poder-se-ia ir além, nos dias de hoje: não seria esta percepção, embrionária em Maleita, que resultaria na Crônica da casa assassinada? Não seria esta condição regional observada pela crítica da época presente na obra muito mais relacionada a um estatuto generalista de região subdesenvolvida? E, desta forma, não estaria Lúcio Cardoso estabelecendo as bases da universalidade de seu universo literário sob a simulação de um a mbiente regional característico? É por acreditar na importância do questionamento para o desenvolvimento da pesquisa que este estudo encerra 
sua jornada deixando lacunas a serem preenchidas por novos olhares, desejando que a litera tura provocadora e hostil de Lúcio Cardoso mexa ta mbém com o imaginário de novos leitores.

\section{REFERÊNCIAS}

AUST, Hugo. O romance histórico e suas formas. In MELLO, Ana Lisboa; MONTEIRO, Charles; MADARASZ, Norman Roland (orgs.). Literatura e História: encontros contemporâneos. Porto Alegre: Gradiva, 2016.

BOSI, Alfredo. História concisa da literatura brasileira. 37 ed. São Paulo: Cultrix, 1994.

BURKE, Peter. A escrita da História: novas perspectivas. Pete Burke (org.); trad. de Magda Lopes. São Paulo: UNESP. 1992.

CARDOSO, Lúcio. Maleita. Rio de Janeiro: Civilização

Brasileira, 2005

CHEVALIER, Jean e GHEERBRANT, Alain (orgs). Diccionário de los Símbolos. Trad: Manuel Silvar y Arturo Rodríguez. Barcelona: Herder, 1998.

LUKÁCS, György. 0 romance histórico. Tradução de Rubens Enderle. São Paulo: Boitempo, 2011
SANTOS, Cássia dos. Polêmica e controvérsia em Lúcio

Cardoso. São Paulo: Mercado das Letras, 2001

\section{Polêmica e controvérsia: o itinerário de Lúcio}

Cardoso de Maleita a 0 Enfeitiçado. Dissertação de Mestrado, Campinas, 1997

SILVA, Carlos Roberto da. No rumo(r) do rio: notas de leitura de Maleita, de Lúcio Cardoso. Revista Alpha, Patos de Minas, n 14, p. 18-26, novembro de 2013

SODRÉ, Nelson Werneck. História da literatura brasileira 9. ed. Rio de Janeiro: Bertrand Brasil, 1995.

Recebido em: 02/02/2020 Aceito em: 06/06/2020 